\title{
Contextualizing Public Stigma: Endorsed Mental Health Treatment Stigma on College and University Campuses
}

\author{
Authors: S. Michael Gaddis ${ }^{1}$, Daniel Ramirez ${ }^{2}$, and Erik Hernandez ${ }^{2}$ \\ 1 - UCLA, Department of Sociology and California Center for Population Research \\ 2 - The Pennsylvania State University, Department of Sociology
}

\section{Forthcoming in Social Science \& Medicine}

Abstract: Scholars suggest that public mental health stigma operates at a meso-level and is associated with severity of symptoms, disclosure, self-esteem, and treatment-seeking behavior. However, the operationalization of public stigma nearly always comes from an individual-level generalization of what others believe. Using data from over 60,000 students on 75 U.S. college and university campuses between 2009-2015, we contextualize public stigma by creating a school-level measure of students' individual-level endorsed mental health treatment stigma. We present multilevel logistic regression models for 21 different dependent variables. We find that even after controlling for individual-level stigma scores, school-level stigma is negatively associated with self-reports of suicidal ideation and self-injury, although not associated with screens for depression or anxiety. Moreover, school-level stigma is negatively associated with medication use, counseling and therapy visits, and to a lesser degree, informal support. We suggest that future research should continue to examine the contextual environment of public stigma, while policymakers may be able to implement changes to significantly reduce stigma at this level.

Keywords: United States, stigma, mental health, higher education, institutional context

Acknowledgments: Thanks to the Healthy Minds Study staff at the University of Michigan, the Robert Wood Johnson Foundation Scholars in Health Policy program, and Daniel Eisenberg, Sarah K. Lipson, Adam Kern, Heather Kugelmass, Colleen Carey, Rob McGrath, Rene Flores, Nicole Hair, Jake Haselswerdt, Rachel Best, Sarah Miller, and Francisco Pedraza. 


\section{INTRODUCTION}

“For stigma research to move forward, sociologists and other stigma researchers need to...pursue innovative directions that define critical agendas to understand and alter the landscape of stigma.” Pescosolido and Martin 2015.

Since Erving Goffman’s (1963) seminal work on the topic, the volume of research on stigma has rapidly expanded, spawning multiple major review articles in the past two decades alone (Clement et al. 2015; Corrigan, Druss, and Perlick 2014; Gulliver, Griffiths, and Christensen 2010; Link and Phelan 2001; Major and O’Brien 2005; Parcesepe and Cabassa 2013; Pescosolido and Martin 2015). This heightened attention is, in part, due to the important associations between stigma and the severity of mental illness symptoms (Andrade et al. 2014; Brown 2017; Drapalski et al. 2013), disclosure of conditions to friends, family, and healthcare professionals (Dew et al. 2007; Donnelly 2017; Prior et al. 2003), self-esteem (Corrigan 2004; Corrigan and Watson 2002; Corrigan, Watson, and Barr 2006), and treatment-seeking behavior (Clement et al. 2015; Tsang, Fung, and Chung 2010; Vogel, Wade, and Haake 2006). While population estimates suggest that many individuals with symptoms of mental illness do not receive treatment or are undertreated (Kessler et al. 2005; Wang et al. 2005, 2007), scholars, healthcare providers, and other stakeholders hope that stigma reduction efforts will increase treatment-seeking behavior (Clair, Daniel, and Lamont 2016; Hatzenbuehler, Phelan, and Link 2013; Hunter et al. 2017; Pilgrim and Rogers 2005).

Stigma can operate at the micro-, meso-, and macro- levels, often conceptualized as selfstigma, public stigma, and structural stigma, respectively (Pescosolido and Martin 2015), although some debate exists regarding these labels (also see Corrigan and Kosyluk 2014). However, scholars have fallen short in adequately capturing a true meso-level of stigma. Some 
suggest that public stigma "attempts to map the levels and nature of stigma in the general population” (Pescosolido and Martin 2015; 94) and the concept of public stigma has been used to examine cross-national differences and changes within societies over time (Angermeyer and Dietrich 2006; Pescosolido and Martin 2007; Pescosolido et al. 2013). Others link public stigma to a group or community level and suggest that this type of stigma may only apply to specific groups, locations, and periods (Livingston and Boyd 2010; Quinn and Chaudoir 2009; Vogel, Wade, and Hackler 2007). However, previous operationalizations of public stigma ask individual respondents to report on perceived stigma from a generic "most people" originally used in Bruce Link’s (1987; Link, Mirotznik, and Cullen 1991) Devaluation-Discrimination scale, with few exceptions (Moses 2010; also see Eisenberg et al. 2009 for discussion of this issue). These inconsistencies regarding the level of analysis at which public stigma truly takes place perhaps explain the mixed findings on whether public stigma has a positive, negative, or no association with severity of symptoms, disclosure, self-esteem, and treatment (Corrigan et al. 2016; Eisenberg et al. 2009; Golberstein, Eisenberg, and Gollust 2008, 2009; Hunter et al. 2017; Sirey et al. 2001).

A true meso-level measurement of stigma must account for the specific context of the time and place of individuals. Rather than simply measuring individual perceptions of others' stigma, we suggest that a true measure of public stigma should contextualize the aggregate environment of individual self-beliefs about stigma at a specific time and in a specific place. As scholars have suggested in a wide-ranging literature on neighborhood and school contextual effects, individual characteristics and aggregated individual characteristics at the group level may each have their own influence on social processes and outcomes (Harding 2003; Jencks and Mayer, 1990; Kubzansky et al. 2005; Lauen and Gaddis 2013; Sampson, Morenoff, and GannonRowley 2002; Sharkey et al., 2012). In fact, recent work has highlighted the link between 
community-level prejudice and health outcomes (Blair and Brondolo 2017; Orchard and Price 2017). Moreover, researchers have found a variety of contextual effects on mental health outcomes (Hill and Maimon 2013; Ivory et al. 2011; Leventhal and Brooks-Gunn 2003; Schulz et al. 2000) including on college and university campuses (Byrd and McKinnery 2012). Surprisingly, however, no research has examined public stigma in a contextualized manner.

In this article we empirically examine the associations between public stigma operating at the meso-level context and (1) self-reports of and screens for mental health conditions, (2) formal treatment-seeking behavior, and (3) informal support. We leverage differences across four mental health conditions - depression, anxiety, self-injury, and suicidal ideation - to suggest that associations with levels of contextualized public stigma may indicate underreporting rather than true lower prevalence of mental health conditions. We then examine the associations between contextualized public stigma and both formal treatment - medication use or counseling and therapy visits - and informal support to highlight the broader detrimental effects of stigma. We conduct our analyses using data from the Healthy Minds Study (HMS), which has surveyed college students about a broad range of mental health topics since 2007. Although the HMS began in 2007, the questions on stigma are only comparable from the 2009 data collection year and beyond. Below, we briefly discuss the reasons why the college and university campus setting is an appropriate avenue to study contextualized public stigma.

\section{The College and University Campus Context}

We chose college and university campuses as our means of examining contextualized public stigma for three primary reasons. First, research highlights important links between the young adulthood stage of the life course and the onset of symptoms of mental illness. The first onset of most lifetime mental illnesses occurs by an individual's mid-20s (Kessler et al. 2007). 
Approximately 25\% of all individuals who develop mood disorders have done so by age 18 , whereas $75 \%$ of all individuals who develop an anxiety disorder have done so by age 21 and $75 \%$ of all individuals who develop any mental health disorder have done so by age 24 (Jones 2013). Previous studies find that not only are mental health conditions prevalent among undergraduate students, but self-reports of treatment-seeking behavior are low (Eisenberg, Golberstein, and Gollust 2007; Eisenberg, Gollust, Golberstein, and Hefner 2007; Eisenberg, Hunt, and Speer 2013).

Second, in many important ways, college and university campus contexts share similarities with other contexts previously studied. The environmental contexts of college and university campuses vary greatly, much like those of neighborhoods and K-12 schools where environmental contexts have been shown to affect academic, social, and health outcomes (Harding 2003; Sampson, 2008; Sharkey et al., 2012). Like neighborhoods and K-12 schools, young people on college and university campuses often spend a lot of time in a specific location, live nearby, and have intense and sustained interactions within that environment for eight to twelve months a year. In this respect, if contextualized public stigma matters anywhere, it should be in the types of environments in which we already know context matters greatly.

Finally, we chose college and university campuses because of the availability of high quality survey data over multiple years for this context. The HMS data have been used in over fifty peer-reviewed publications to date and are arguably the best available to examine mental health in higher education. The HMS collects large representative samples from each campus and asks a battery of questions about mental health conditions, stigma, and treatment. These rich data allow us to contextual public stigma in a way that other data cannot. Previous research has already begun to examine important differences across college and universities at the meso-level and we continue that tradition here (Lipson et al. 2015). 


\section{RESEARCH QUESTIONS}

We focus on three research questions:

(1) Is contextualized public stigma against mental health treatment at the school-level associated with self-reports of and screens for mental health conditions?

(2) Is contextualized public stigma against mental health treatment at the school-level associated with formal treatment-seeking behavior in the form of medication use and counseling and therapy visits?

(3) Is contextualized public stigma against mental health treatment at the school-level associated with informal support?

Prior work makes it somewhat unclear in what direction we might expect some of these associations to work. We separate self-reports of and screens for mental health conditions because contextualized public stigma may, through social desirability bias, encourage underreporting of mental health conditions, particularly severe ones such as self-injury and suicidal ideation. At the same time, it may be harder for students to underreport depression and anxiety since they are measured with screening tools rather than single self-reported items. The vast prior literature strongly suggests that contextualized public stigma should be negatively associated with formal treatment-seeking behavior, but is less clear on informal support. Environments with high contextualized public stigma may be associated with higher informal support if students are less likely to pursue formal avenues of treatment.

\section{DATA, MEASURES, AND METHODS}

Sample 
This study makes use of four broad sources to develop our analysis: the Healthy Minds Study (HMS), Barron’s Online Profiles of American Colleges (Barron’s), the Integrated Postsecondary Education Data System (IPEDS), and the U.S. News and World Report (USNWR). The primary source, the HMS dataset, is an annual web-based survey including random samples of students from over 100 colleges and universities from the US. Web-based surveys are generally considered valuable for examining sensitive topics and in reducing social desirability bias (Aday 1996; McCabe 2004).

The HMS collects data on mental health and similar issues, such as depression, anxiety, and substance use disorders, as well as service utilization by respondents. Given the interest of the study lies mainly in colleges and universities, we exclude professional and specialized institutions such as art and design schools, and medical schools. Ultimately, the sample for this analysis includes 62,756 students at 75 unique institutions that participated in the study between 2009 and 2015. We supplement the HMS student-level data with school-level variables from Barron's, IPEDS, and USNWR.

\section{School-Level Variables}

Our primary independent variable of interest is a calculated mean endorsed mental health treatment stigma scale score for each college or university. Students were asked to rate the following 3 questions on a five-point Likert scale (strongly agree to strongly disagree): (1) “I would willingly accept someone who has received mental health treatment as a close friend.” (2) “I would think less of a person who has received mental health treatment.” (3) "I feel that receiving mental health treatment is a sign of personal failure.” We reverse coded item 1 and summed these three variables for each student to construct an individual endorsed mental health 
treatment stigma scale score. We then calculated the mean of these individual scores at each college or university.

Our multilevel analyses include six other school-level controls: type of housing, public/private, admissions selectivity, school enrollment size, and type of institutional program. The type of housing variable comes from IPEDS, captures the proportion of students living in campus-owned, -operated, or -affiliated housing, and has values of nonresidential, residential, or highly residential. The sector variable comes from USNWR and has the values of public or private. The admissions selectivity variable comes from Barron’s and has values of noncompetitive, less competitive, competitive, very competitive, highly competitive, and most competitive. The school enrollment size variable comes from IPEDS, captures the Carnegie Foundation's definition of institutional size, and has values of small ( $<3,000$ students), medium (3,000-9,999 students), and large ( $\geq 10,000$ students). The institutional type variable comes from IPEDS and has values of doctorate-granting, master's, or baccalaureate only.

\section{Mental Health Outcomes}

We examine four sets of mental health outcomes: (1) self-reports and screens for mental health conditions, (2) medication use, (3) counseling and therapy visits, and (4) informal support. The mental health conditions include five binary variables identifying if respondents screen positive for depression (PHQ-9), screen positive for anxiety (PHQ anxiety module and GAD-7), self-report having thoughts of suicide during the past twelve months, self-report self-injurious behavior during the past four weeks, or have a positive response on one or more of these four mental health conditions (any). The medication outcomes are four binary variables identifying if respondents have taken anti-depressants, anxiety medication, sleep medication, psychostimulants, or one or more medications in the last twelve months (any). The counseling 
and therapy outcomes consist of four binary variables identifying if respondents have sought counseling of therapy from their institution's student services, a local provider outside their institution, a provider in their hometown, or any health professional for their mental or emotional health in the last twelve months. The final group of outcomes on informal support includes seven binary variables identifying if respondents received counseling or support for their mental or emotional health from a family member, religious counselor or religious contact, support group, a friend, a roommate, a significant other, or any informal source in the last twelve months. See Table 1 for a full list and descriptions of these twenty-one dependent variables.

\section{Individual-Level Controls}

Our analyses also include controls for individual-level characteristics. These include mother's and father's educational attainment (years of school), race, gender, age, survey year, and the individual endorsed mental health treatment stigma scale score. The stigma scale score, described in more detail above, has a range of 1 to 15. See Table 1 for a full list and descriptions of individual-level controls.

\section{Method of Analysis}

We estimate multilevel logistic regressions with random intercepts for each of the mental health outcomes of interest. This procedure allows us to calculate net effects of school-level characteristics on the likelihood of reporting a mental health condition, while controlling for both cross-school and individual-level characteristics (Raudenbush and Bryk 2001). According to the intra-class correlation calculations for each of the models, there is sufficient variation across schools to justify the use of multilevel modeling. When modeling mental health conditions as dependent variables, our analysis sample includes all 62,576 students. However, when modeling 
formal treatment or informal support outcomes, we choose to restrict our sample to only those who have a mental health condition (as characterized by a positive response on one or more of the four mental health conditions: depression screen, anxiety screen, self-injury self-report, or suicidal ideation self-report). When modeling medication use outcomes, this reduces our sample size to 21,128; when modeling counseling and therapy visits or informal support outcomes, this reduces our sample size to 19,400. Additionally, our analysis only includes 68 colleges and universities because 7 did not participate in the treatment and informal support modules.

\section{RESULTS}

Descriptive Analysis

Tables 2 and 3 show descriptive statistics for the school- and individual-level variables respectively. The school-level descriptive statistics suggest that although schools select into the HMS, we still see significant variation across several important characteristics in the dataset. Figure 1 shows the variation in school-level prevalence of the "any" version of our four types of outcomes (mental health conditions, medication use, seeking counseling or therapy, and informal support). We find significant variation across schools on all four types of measures. Prevalence of any mental health condition ranges from $25.2 \%$ to $50.5 \%$, with a mean of $35.2 \%$. Any medication use ranges from $4.1 \%$ to $18.7 \%$, with a mean of $10.3 \%$. Any counseling or therapy ranges from $5.3 \%$ to $21.4 \%$, with a mean of $11.2 \%$. Any informal support ranges from $18.6 \%$ to $42.1 \%$, with a mean of $28.8 \%$. Figure 2 shows fitted lowess curves of the school-level prevalence of the four "any" measures of outcomes on the y-axis against school-level mean endorsed mental health treatment stigma scores on the x-axis. This examination at the school-level suggests a negative association between school-level stigma and prevalence of mental health conditions, medication use, counseling or therapy visits, and informal support. 


\section{Logistic Regression Analysis}

In Table 4, we report odds-ratio results of multilevel logistic regression analyses predicting an individual respondent's (1) screen for depression, (2) screen for anxiety, (3) selfreport of suicidal ideation, (4) self-report of self-injury, and (5) any mental health condition. All models control for a host of individual- and school-level controls. The results suggest that while the individual-level stigma score is positively associated with all five dependent variables, the school-level mean stigma score has negative associations and only with the single-item selfreport dependent variables. Students on campuses with higher school-level mean stigma scale scores are less likely to report thoughts of suicide or self-injurious behavior, but there is no association between school-level mean stigma scale scores and screens for depression or anxiety.

In Table 5, we show similar models with medication use as the dependent variables. However, in these models we include only students who have a mental health condition according to our "any" variable, essentially adjusting for the prior negative association between school-level stigma and mental health conditions. Once again, we find negative associations between the school-level mean stigma scale score and the dependent variables, even while controlling for individual-level stigma score and individual- and school-level controls. Students on campuses with higher school-level mean stigma scale scores are less likely to report taking medication for depression or anxiety, or any medication. Additionally, there is a marginally significant negative association between the school-level mean stigma scale score and taking psychostimulants.

In Tables 6 and 7, we report odds-ratio results of multilevel logistic regression analyses predicting an individual's likelihood to seek counseling and therapy (Table 6) and informal support (Table 7) for mental health conditions. Among three of the four dependent variables for 
counseling and therapy, we find negative associations between the school-level mean stigma scale score and the dependent variables, with particularly large and strong negative effects on counseling or therapy services from the institution. The results for seeking informal support are much more mixed. We find negative associations between the school-level mean stigma scale score and talking to a family member, friend, significant other, or any informal support. However, we do not find significant associations with talking to a roommate or support group. Moreover, we find a marginally significant positive association between the school-level mean stigma scale score and seeking informal support through a religious group.

Because we find that school-level mean stigma scale scores are differentially associated with self-report versus screens of mental health conditions, we chose to run a series of robustness checks. We analyzed models similar to those presented in Tables 5 through 7 but instead restricted our sample in one version to only those who had a mental health condition based on a self-report and in a second version to only those who had a mental health condition based on a positive screen. We find no differences across these types of models. These results are available from the authors upon request.

\section{CONCLUSION AND DISCUSSION}

Scholars have devoted much attention to mental health stigma, noting that stigma operates at the micro-, meso-, and macro- levels. Known as public stigma at the meso-level, it is often operationalized as an individual response about what "most people” think. However, considering local and community context and measuring public stigma at the proper level of analysis may help elucidate the impact and mechanisms of public stigma. In this research, we contextualized public stigma by creating a school-level measure of students’ individual-level endorsed mental health treatment stigma. We found that even after controlling for individual- 
level stigma scores, school-level stigma is negatively associated with self-reports of suicidal ideation and self-injury, although not associated with screens for depression or anxiety. We believe that it is likely that higher levels of contextualized public stigma do not reduce the prevalence of mental health conditions but lead students to underreport these conditions. Moreover, school-level stigma is negatively associated with medication use, counseling and therapy visits, and to a lesser degree, informal support.

Our research has strong implications for higher education administrators, staff, and healthcare providers. The meso-level of stigma likely represents a very important conduit for improving individual mental health, treatment seeking-behavior, and adherence. Communities and organizations might not be able to influence the broader macro-levels of opinions and beliefs about mental illness, but they can enact policies and campaigns to influence local environments. Additionally, individuals may care more about what their local reference group peers think than the generalized other. As an example that merges these ideas, we might imagine that the context of stigma against mental health treatment on a single college or university campus could be influenced by an institutional campaign to reduce stigma via flyers highlighting the prevalence of mental health conditions among the local student body. By targeting all individuals, rather than just those with mental health conditions, the campaign might be successful at changing the entire campus climate surrounding stigma. In fact, many researchers have discussed and documented the importance of similar types of processes in meso-level contexts to help reduce mental illness stigma (Cook et al. 2014; Corrigan and Fong 2014; Kosyluk et al. 2016; Thornicroft et al. 2016). Research suggests that among college students, efforts at mental health education are more effective in reducing stigma than efforts at increasing contact with others who have a mental health condition and overall, targeted interventions are more effective than broad interventions (Mittal et al. 2012; Thornicroft et al. 2016). These findings suggest that colleges and universities 
might reduce stigma by investing in localized anti-stigma campaigns with physical and digital materials conveying facts and statistics about mental health. Reducing stigma is particularly important given the strong negative association between school-level stigma and use of an institution's services for counseling or therapy.

This research also has implications for other scholars studying mental health. If public stigma is negatively associated with reports of mental health conditions and treatment in other contexts, researchers must be cautious to interpret population-level statistics. Survey data of selfreports may underestimate true levels of mental health conditions and do so unevenly across populations, neighborhoods, and communities. Scholarly work on mental health and stigma would likely benefit from including contextualized measures of public stigma whenever possible, and researchers should consider data collection designs that allow them to capture contextualized measures of public stigma as well. More research comparing self-reports, institutional records, and other modes of data collection would help scholars adjudicate these issues as well (Cernat, Couper, and Ofstedal 2016; Rhodes et al. 2006).

\section{Limitations \& Directions for Future Research}

We caution readers that we cannot make claims about causality in this article. While it is possible that the contextual levels of public stigma on college and university campuses directly impact students' likelihoods of reporting mental health conditions, seeking formal treatment, and seeking informal support, it is also possible that the causal arrow goes in the opposite direction. A higher proportion of students who do not have mental health conditions may drive up public stigma on campuses, however this “contact hypothesis” remains unresolved itself (see Eisenberg, Downs, and Golberstein 2012). We believe that recent research on the causal direction of public stigma and mental health (Kendra 2013) as well as our own differences in findings between self- 
report and screen measures hints at the causal direction and we suggest that future research should more thoroughly investigate this in a causal framework.

A second limitation concerns the selection of schools into the HMS. Although the student respondents are representative of each college or university, these institutions opt into the HMS each year, often because they are interested in obtaining data about the mental health of their own students. Thus, we must consider that the HMS might not capture schools on the tails of the contextualized public stigma scale - schools where things are going so well on campus that administrators feel no need to pay for the HMS, or schools where things are going so poorly precisely because administrators are not paying attention to mental health on campus. Other researchers may be able to collect data that gives us a better understanding of the entire distribution of contextualized public stigma

Finally, our study does not go into detail about the mechanisms of contextualized public stigma and differences between institutions that lead to variation in contextualized public stigma. Literature on a variety of contextual effects generally suggests that individual actors need not know about all others’ individual characteristics. Instead, the aggregated individual characteristics are reflected in the contextual environment through motivation, involvement, expectations, and resources, among other things. In the campus environment, we might imagine that student, faculty, and staff attitudes and beliefs about mental health are enacted through comments and other reactions around campus. Additionally, resources and policies, particularly those related to insurance, service availability, and fees, almost certainly contribute to differences in contextualized public stigma across campuses. Although the HMS lacks data on such institutional characteristics, we have designed supplemental data collection around the HMS, dubbed the Healthy Minds Study Institutional Website Supplement, to broaden the range of research questions scholars can ask about institutional contributions to student mental health. It is 
our hope that in future research we can examine what characteristics contribute to contextualized public stigma and provide a roadmap to creating policies to reduce stigma on campuses. 


\section{REFERENCES}

Aday, L.A. 1996. Designing and Conducting Health Surveys ( $2^{\text {nd }}$ ed.). San Francisco, CA: Jossey-Bass.

Andrade, L.H., et al. 2014. "Barriers to Mental Health Treatment: Results from the WHO World Mental Health Surveys.” Psychological Medicine, 44:1303-17.

Angermeyer, M. C., and S. Dietrich. 2006. "Public Beliefs about and Attitudes Towards People with Mental Illness: A Review of Population Studies.” Acta Psychiatrica Scandinavica, 113:163-79.

Blair, Irene V., and Elizabeth Brondolo. 2017. "Moving Beyond the Individual: Community-level Prejudice and Health." Social Science and Medicine, (In-Press).

Brown, Robyn L. 2017. "Understanding the Influence of Stigma and Discrimination for the Functional Limitation Severity - Psychological Distress Relationship: A Stress and Coping Perspective.” Social Science Research, 62:150-60.

Byrd, DeAnnah R., and Kristen J. McKinney. 2012. "Individual, interpersonal, and institutional level factors associated with the mental health of college students." Journal of American College Health, 60(3):185-193.

Carnegie Foundation for the Advancement of Teaching. Carnegie Classifications. Available at: http://carnegieclassifications.iu.edu/. Accessed April 20, 2017.

Cernat, Alexandru, Mick P. Couper, and Mary Beth Ofstedal. 2016. "Estimation of mode effects in the Health and Retirement Study using measurement models." Journal of Survey Statistics and Methodology, 4(4):501-524.

Clair, Matthew, Caitlin Daniel, and Michele Lamont. 2016. "Destigmatization and Health: Cultural Constructions and the Long-term Reduction of Stigma." Social Science \& Medicine, 165:223-32.

Clement, S., O. Schauman, T. Graham, F. Maggioni, S. Evans-Lacko, N. Bezborodovs, C. Morgan, N. Rusch, J. S. L. Brown, and G. Thornicroft. 2015. "What is the Impact of Mental Health-Related Stigma on Help-Seeking? A Systematic Review of Quantitative and Qualitative Studies.” Psychological Medicine, 45:11-27.

Cook, Jonathan E., Valerie Purdie-Vaughns, Ilan H. Meyer, and Justin T. A. Busch. 2014. "Intervening Within and Across Levels: A Multilevel Approach to Stigma and Public Health.” Social Science \& Medicine, 103:101-9.

Corrigan, Patrick W. 2004. "How Stigma Interferes with Mental Health Care.” American Psychologist, 59(7):614-25.

Corrigan, Patrick W., Benjamin G. Druss, and Deborah A. Perlick. 2014. "The Impact of Mental Illness Stigma on Seeking and Participating in Mental Health Care.” Psychological Science in the Public Interest, 15(2):37-70.

Corrigan, Patrick W., and Mandy W. M. Fong. 2014. "Competing Perspectives on Erasing the Stigma of Illness: What Says the Dodo Bird?” Social Science \& Medicine, 103:110-7.

Corrgian, Patrick W., and Kristin A. Kosyluk. 2014. "Mental Illness Stigma: Types, Constructs, and Vehicles for Change.” In P.W. Corrigan (Ed.) The Stigma of Disease and Disability: Understanding Causes and Overcoming Inustices, p 35-56.

Corrigan, Patrick W., Kristin A. Kosyluk, Fred Markowitz, Robyn Lewis Brown, Bridget Conlon, Jo Rees, Jessica Rosenberg, Sarah Ellefson, and Maya Al-Khouja. 2016. "Mental Illness Stigma and Disclosure in College Students.” Journal of Mental Health, 25(3):224-30.

Corrigan, Patrick W., and Amy C. Watson. 2002. "The Paradox of Self-Stigma and Mental Illness.” Clinical Psychology: Science and Practice, 9(1):35-53. 
Corrigan, Patrick W., and Amy C. Watson, and Leah Barr. 2006. "The Self-Stigma of Mental Illness: Implications for Self-Esteem and Self-Efficacy.” Journal of Social and Clinical Psychology, 25(9):875-84.

Dew, Kevin, Sonya Morgan, Anthony Dowell, Deborah McLeod, John Bushnell, and Sunny Collings. 2007. “'It Puts Things Out of Your Control': Fear of Consequences as a Barrier to Patient Disclosure of Mental Health Issues to General Practitioners.” Sociology of Health \& Illness, 29(7):1059-74.

Diez-Quevedo C, Rangil T, Sanchez-Planell L, Kroenke K, Spitzer RL. 2001. "Validation and utility of the patient health questionnaire in diagnosing mental disorders in 1003 general hospital Spanish inpatients." Psychosom Med. 63:679-686.

Donnelly, Colleen. 2017. "Public Attitudes toward Disclosing Mental Health Conditions.” Social Work in Mental Health, DOI: 10.1080/15332985.2017.1302039

Drapalski, Amy L., Alicia Lucksted, Paul B. Perrin, Jennifer M. Aakre, Clayton H. Brown, Bruce R. DeForge, and Jennifer E. Boyd. 2013. “A Model of Internalized Stigma and its Effect on People with Mental Illness.” Psychiatric Services, 64(3):264-9.

Eisenberg, Daniel, Marilyn F. Downs, and Ezra Golberstein. 2012. "Effects of Contact with Treatment Users on Mental Illness Stigma: Evidence from University Roommate Assignments.” Social Science \& Medicine, 75(6):1122-1127.

Eisenberg, Daniel, Marilyn F. Downs, Ezra Golberstein, and Kara Zivin. 2009. "Stigma and help seeking for mental health among college students.” Medical Care Research and Review, 66(5):522-541.

Eisenberg, Daniel, Ezra Golberstein, and Sarah E. Gollust. 2007. "Help-seeking and access to mental health care in a university student population.” Medical Care, 45(7): 594-601.

Eisenberg, Daniel, Sarah E. Gollust, Ezra Golberstein, and Jennifer L. Hefner. 2007. "Prevalence and correlates of depression, anxiety, and suicidality among university students.”

American Journal of Orthopsychiatry, 77(4):534-542.

Eisenberg, Daniel, Justin Hunt, and Nicole Speer. 2013. "Mental health in American colleges and universities: variation across student subgroups and across campuses.” The Journal of Nervous and Mental Disease, 201(1):60-67.

Goffman Erving. 1963. Stigma: Notes on the Management of Spoiled Identity. Englewood Cliffs, NJ: Prentice-Hall.

Golberstein, Ezra, Daniel Eisenberg, and Sarah E. Gollust. 2008. "Perceived stigma and mental health care seeking.” Psychiatric Services, 59(4):392-399.

Golberstein, Ezra, Daniel Eisenberg, and Sarah E. Gollust. 2009. "Perceived Stigma and Help-Seeking Behavior: Longitudinal Evidence from the Healthy Minds Study.” Psychiatric Services, 60(9):1254-6.

Gulliver, Amelia, Kathleen M. Giffiths, and Helen Christensen. 2010. "Perceived Barriers and Facilitators to Mental Health Help-Seeking in Young People: A Systematic Review.” BMC Psychiatry, 10:113.

Harding, David J. 2003. "Counterfactual Models of Neighborhood Effects: The Effect of Neighborhood Poverty on Dropping Out and Teenage Pregnancy.” American Journal of Sociology, 109(3):676-719.

Hatzenbuehler M. L., J. C. Phelan, and B. G. Link. 2013. "Stigma as a fundamental cause of population health inequalities.” American Journal of Public Health, 103:813-21.

Hill, Terrence D., and David Maimon. 2013. "Neighborhood context and mental health.” In Handbook of the Sociology of Mental Health, pp. 479-501. Springer Netherlands. 
Hunter, Bronwyn A., et al. 2017. "Socio-Psychological Mediators of the Relationship between Behavioral Health Stigma and Psychiatric Symptoms.” Social Science \& Medicine, 181:177-83.

Ivory, Vivienne C., Sunny C. Collings, Tony Blakely, and Kevin Dew. 2011. "When does neighbourhood matter? Multilevel relationships between neighbourhood social fragmentation and mental health.” Social Science \& Medicine, 72(12):1993-2002.

Jencks, Christopher, and Susan E. Mayer. 1990. "The Social Consequences of Growing up in a Poor Neighborhood: A Review.” In M. McGeary \& L. Lynn (Eds.), Inner City Poverty in the United States. Washington, DC: National Academy Press.

Jones, P.B. 2013. “Adult Mental Health Disorders and Their Age at Onset.” British Journal of Psychiatry, 202(S54):S5-10.

Kendra, Matthew Stephen. 2013. Mental Illness Symptoms and Mental Illness Stigma: A Test of Bidirectional Influences. Unpublished dissertation. George Mason University.

Kessler et al. 2005. "Prevalence and Treatment of Mental Disorders, 1990 to 2003.” The New England Journal of Medicine, 352(42):2515-23.

Kessler, Ronald C., G. Paul Amminger, Sergio Aguilar-Gaxiola, Jordi Alonso, Sing Lee, and T. Bedirhan Ustun. 2007. "Age of Onset of Mental Disorders: A Review of Recent Literature.” Current Opinion in Psychiatry, 20(4):359-64.

Kosyluk, Kristin A., et al. 2016. "Challenging the Stigma of Mental Illness among College Students.” Journal of Adolescent Health, 59:325-31.

Kubzansky, Laura D., et al. 2005. "Neighborhood Contextual Influences on Depressive Symptoms in the Elderly.” American Journal of Epidemiology, 162(3):253-60.

Lauen, Douglas L., and S. Michael Gaddis. 2013. "Exposure to Classroom Poverty and Test Score Achievement: Contextual Effects or Selection?” American Journal of Sociology, 118(4):943-79.

Leventhal, Tama, and Jeanne Brooks-Gunn. 2003. "Moving to opportunity: an experimental study of neighborhood effects on mental health.” American Journal of Public Health, 93(9):1576-1582.

Link, Bruce G. 1987. "Understanding Labeling Effects in the Area of Mental Disorders: An Assessment of the Effects of Expectations of Rejections.” American Sociological Review, 52:96-112.

Link, Bruce G., Jerrold Mirotznik, and Francis T. Cullen. 1991. “The effectiveness of stigma coping orientations: can negative consequences of mental illness labeling be avoided?” Journal of Health and Social Behavior, 32(3):302-320.

Link, Bruce, and Jo C. Phelan. 2001. “Conceptualizing Stigma.” Annual Review of Sociology, 27:363-85.

Lipson, Sarah K., S. Michael Gaddis, Justin Heinze, Kathryn Beck, and Daniel Eisenberg. 2015. "Variation in Student Mental Health and Treatment Utilization Across US Colleges and Universities.” Journal of American College Health, 63(6):388-96.

Livingston J.D., and J. E. Boyd. 2010. "Correlates and consequences of internalized stigma for people living with mental illness: a systematic review and meta-analysis.” Social Science \& Medicine, 71:2150-61.

Löwe B, Gräfe K, Zipfel S, Witte S, Loerch B, Herzog W. 2004. "Diagnosing ICD-10 depressive episodes: superior criterion validity of the Patient Health Questionnaire. Psychother Psychosom 73:386-390.

Major B, O’Brien LT. 2005. “The Social Psychology of Stigma.” Annual Review of Psychology, 56:393-421. 
McCabe, S. E. 2004. "Comparison of Web and Mail Surveys in Collecting Illicit Drug Use Data: A Randomized Experiment.” Journal of Drug Education, 34:61-72.

Mittal, Dinesh, Greer Sullivan, Lakshminarayana Chekuri, Elise Allee, and Patrick W. Corrigan. 2012. "Empirical studies of self-stigma reduction strategies: a critical review of the literature.” Psychiatric Services, 63(10):974-981.

Moses, Tally. 2010. "Being Treated Differently: Stigma Experiences with Family, Peers, and School Staff among Adolescents with Mental Health Disorders.” Social Science \& Medicine, 70(7):985-93.

Orchard, Jacob, and Joseph Price. 2017. "County-Level Racial Prejudice and the Black-White Gap in Infant Health Outcomes.” Social Science \& Medicine, 181:191-8.

Parcesepe, Angela M., and Leopoldo J. Cabassa. 2013. "Public Stigma of Mental Illness in the United States: A Systematic Review.” Administration and Policy in Mental Health, 40(5):384-99.

Pescosolido, Bernice A., and Jack K. Martin. 2007. “Stigma and the sociological enterprise.” In Mental Health, Social Mirror, ed. WR Avison, JD McLeod, BA Pescosolido, pp. 307-28. New York: Springer.

Pescosolido, Bernice A., and Jack K. Martin. 2015. “The Stigma Complex.” Annual Review of Sociology, 41:87-116.

Pescosolido, Bernice A., Tait R. Medina, Jack K. Martin, and J. Scott Long. 2013. “The 'Backbone' of Stigma: Identifying the Global Core of Public Prejudice Associated with Mental Illness.” American Journal of Public Health, 103(5):853-60.

Pilgrim, David, and Anne E. Rogers. 2005. "Psychiatrists as Social Engineers: A Study of an Anti-Stigma Campaign.” Social Science \& Medicine, 61: 2546-2556.

Prior, Lindsay, Fiona Wood, Glyn Lewis, and Roisin Pill. 2003. "Stigma Revisited, Disclosure of Emotional Problems in Primary Care Consultations in Wales.” Social Science \& Medicine, 56:2191-2200.

Quinn, Diane M., and Stephenie R. Chaudoir. 2009. "Living with a Concealable Stigmatized Identity: The Impact of Anticipated Stigma, Centrality, Salience, and Cultural Stigma on Psychological Distress and Health.” Journal of Personality and Social Psychology, 97(4):634-51.

Raudenbush, Stephen W. and Anthony Bryk. 2001. Hierarchical Linear Models: Applications and Data Analysis Methods. $2^{\text {nd }}$ Edition. Thousand Oaks. Sage Publications, Inc.

Rhodes, Anne, R. Liisa Jaakkimainen, Susan Bondy, and Kinwah Fung. 2006. "Depression and mental health visits to physicians_-a prospective records-based study.” Social Science \& Medicine, 62(4):828-834.

Sampson, R. J. 2008. "Moving to Inequality: Neighborhood Effects and Experiments Meet Social Structure.” American Journal of Sociology, 114(1):189-231.

Sampson, R. J., J. D Morenoff, and T. Gannon-Rowley. 2002. “Assessing 'Neighborhood Effects’: Social Processes and New Directions in Research.” Annual Review of Sociology, 28:443-78.

Schulz, Amy, et al. 2000. "Unfair treatment, neighborhood effects, and mental health in the Detroit metropolitan area.” Journal of Health and Social Behavior, 41(3):314-332.

Sharkey, Patrick, Nicole Strayer, Andrew Papachristos, Cybele Raver. 2012. "The Effect of Local Violence on Children's Attention and Impulse Control.” American Journal of Public Health, 102:2287-93.

Sirey, Jo Anne, Martha L. Bruce, George S. Alexopoulos, Deborah A. Perlick, Patrick Raue, Steven J. Friedman, and Barnett S. Meyers. 2001. "Perceived stigma as a predictor of 
treatment discontinuation in young and older outpatients with depression.” American Journal of Psychiatry 158(3):479-481.

Thornicroft, Graham, et al. 2016. "Evidence for Effective Interventions to Reduce Mental-Health-Related Stigma and Discrimination.” The Lancet, 387:1123-32.

Tsang, H.W., K. M. Fung, and R. C. Chung. 2010. "Self-stigma and stages of change as predictors of treatment adherence of individuals with schizophrenia.” Psychiatry Research, 180:10-15.

U.S. News and World Report. Best Colleges. Available at: https://www.usnews.com/bestcolleges/rankings.

Vogel D. L., N. G. Wade, and S. Haake. 2006. "Measuring the self-stigma associated with seeking psychological help.” Journal of Counseling Psychology, 53(3):325-7.

Vogel D. L., N. G. Wade, and A. H. Hackler. 2007. "Perceived public stigma and the willingness to seek counseling: the mediating roles of self-stigma and attitudes toward counseling." Journal of Counseling Psychology, 54(1):40-50.

Wang, Philip S., Michael Lane, Mark Olfson, Harold A. Pincus, Kenneth B. Wells, and Ronald C. Kessler. 2005. "Twelve-Month Use of Mental Health Services in the United States." Arch. Gen. Psychiatry, 62:629-40.

Wang, Philip S., et al. 2007. "Use of Mental Health Services for Anxiety, Mood, and Substance Disorders in 17 Countries in the WHO World Mental Health Surveys.” The Lancet, 370:841-50. 
Table 1. Brief Variable Descriptions

\begin{tabular}{|c|c|c|c|}
\hline Variables & Level & Source & Other \\
\hline \multicolumn{4}{|l|}{ Outcomes: Mental Health Condition } \\
\hline Depression & Binary & HMS & PHQ-9 screen \\
\hline Anxiety & Binary & HMS & PHQ anxiety module or GAD-7 screen \\
\hline Suicidal ideation & Binary & HMS & Self-report \\
\hline Self-injury & Binary & HMS & Self-report \\
\hline Any mental health condition & Binary & HMS & Any of above \\
\hline \multicolumn{4}{|l|}{ Outcomes: Medication Use } \\
\hline Depression medication & Binary & HMS & \\
\hline Anxiety medication & Binary & HMS & \\
\hline Sleeping medication & Binary & HMS & \\
\hline Psychostimulants & Binary & HMS & \\
\hline Any mental health medication & Binary & HMS & Any of above \\
\hline \multicolumn{4}{|l|}{ Outcomes: Counseling/Therapy } \\
\hline Counseling & Binary & HMS & \\
\hline Local provider & Binary & HMS & \\
\hline Hometown provider & Binary & HMS & \\
\hline $\begin{array}{l}\text { Any counseling or therapy from health } \\
\text { professional }\end{array}$ & Binary & HMS & Any of above \\
\hline \multicolumn{4}{|l|}{ Outcomes: Informal support } \\
\hline Family member & Binary & HMS & \\
\hline Religious group & Binary & HMS & \\
\hline Support group & Binary & HMS & \\
\hline Friend & Binary & HMS & \\
\hline Roommate & Binary & HMS & \\
\hline Significant other & Binary & HMS & \\
\hline Any informal support & Binary & HMS & Any of above \\
\hline \multicolumn{4}{|l|}{ Individual-level Controls } \\
\hline Age & Ordinal & HMS & $1=18$ and $10=45^{+}$ \\
\hline Mother's educational attainment & Ordinal & HMS & $1=8$ th grade $10=$ Graduate degree \\
\hline Father's educational attainment & Ordinal & HMS & $1=8$ th grade $10=$ Graduate degree \\
\hline Year & Continuous & HMS & \\
\hline Year in school & Continuous & HMS & \\
\hline White/Non-white & Binary & HMS & \\
\hline Female/Male & Binary & HMS & \\
\hline Heterosexual/Non-heterosexual & Binary & HMS & \\
\hline Stigma scale & Scale & HMS & Range: 1 to 15 \\
\hline \multicolumn{4}{|l|}{ School-level variables } \\
\hline Institutional type & Categorical & IPEDS & BA, MA, PhD. \\
\hline Enrollment & Ordinal & IPEDS & $1=$ Small $3=$ Large \\
\hline Sector & Binary & USNWR & $1=$ Public $0=$ Private \\
\hline Housing & Ordinal & IPEDS & 1= Non-residential 3= Highly residential \\
\hline Admissions selectivity & Ordinal & Barron’s & 1= Low competitive 6=Most competitive \\
\hline Mean endorsed stigma scale score & Continuous & HMS & \\
\hline
\end{tabular}


Table 2. School-Level Descriptive Statistics

\begin{tabular}{|c|c|c|c|c|c|}
\hline & & N schools & \% schools & $\mathrm{N}$ students & \% students \\
\hline \multirow{3}{*}{ Institutional Type } & Baccalaureate & 14 & 18.67 & 9,477 & 15.10 \\
\hline & Master’s & 21 & 28.00 & 18,053 & 28.77 \\
\hline & Doctorate & 40 & 53.33 & 35,226 & 56.13 \\
\hline \multirow[t]{3}{*}{ Enrollment Size } & Small & 12 & 16.00 & 6,268 & 9.99 \\
\hline & Medium & 14 & 18.67 & 10,728 & 17.09 \\
\hline & Large & 49 & 65.33 & 45,760 & 72.92 \\
\hline \multirow[t]{2}{*}{$\underline{\text { Sector }}$} & Public & 45 & 60.00 & 37,964 & 60.49 \\
\hline & Private & 30 & 40.00 & 24,792 & 39.51 \\
\hline \multirow[t]{3}{*}{ Housing } & Non-residential & 19 & 25.33 & 12,105 & 19.29 \\
\hline & Residential & 34 & 45.33 & 30,543 & 48.67 \\
\hline & Highly residential & 22 & 29.33 & 20,108 & 32.04 \\
\hline \multirow[t]{5}{*}{ Admissions Selectivity } & Low competitive & 5 & 6.67 & 2,438 & 3.88 \\
\hline & Competitive & 34 & 45.33 & 18,914 & 30.14 \\
\hline & Very competitive & 13 & 17.33 & 11,895 & 18.95 \\
\hline & Highly competitive & 10 & 13.33 & 11,170 & 17.80 \\
\hline & Most competitive & 13 & 17.33 & 18,339 & 29.22 \\
\hline \multirow[t]{2}{*}{ Total } & & 75 & & 62,756 & \\
\hline & & Mean & SD & Min & Max \\
\hline $\begin{array}{l}\text { Mean endorsed stigma scale } \\
\text { score }\end{array}$ & & 2.67 & 0.30 & 1.87 & 3.44 \\
\hline
\end{tabular}


Table 3. Individual-Level Descriptive Statistics

\begin{tabular}{|c|c|c|c|c|}
\hline $\begin{array}{l}\text { Outcomes: Mental Health Conditions } \\
(\mathrm{N}=52,756)\end{array}$ & \% “yes” & SD & Min & Max \\
\hline Depression & 0.17 & 0.37 & 0 & 1 \\
\hline Anxiety & 0.13 & 0.33 & 0 & 1 \\
\hline Suicidal ideation & 0.08 & 0.26 & 0 & 1 \\
\hline Self-injury & 0.17 & 0.37 & 0 & 1 \\
\hline Any Mental Health Condition & 0.34 & 0.47 & 0 & 1 \\
\hline \multicolumn{5}{|l|}{ Outcomes: Medication $(\mathrm{N}=\mathbf{2 1 , 1 2 8 )}$} \\
\hline Any Mental Health Medication & 0.25 & 0.44 & 0 & 1 \\
\hline Depression medication & 0.17 & 0.37 & 0 & 1 \\
\hline Anxiety medication & 0.09 & 0.29 & 0 & 1 \\
\hline Sleeping medication & 0.06 & 0.24 & 0 & 1 \\
\hline Psychostimulants & 0.07 & 0.26 & 0 & 1 \\
\hline \multicolumn{5}{|l|}{$\begin{array}{l}\text { Outcomes: Counseling and Therapy } \\
(\mathrm{N}=19,400)\end{array}$} \\
\hline Counseling & 0.17 & 0.37 & 0 & 1 \\
\hline Local provider & 0.07 & 0.25 & 0 & 1 \\
\hline Hometown provider & 0.10 & 0.29 & 0 & 1 \\
\hline Sought health professional & 0.30 & 0.46 & 0 & 1 \\
\hline \multicolumn{5}{|l|}{$\begin{array}{l}\text { Outcomes: Informal Support } \\
(\mathrm{N}=19,400)\end{array}$} \\
\hline Family member & 0.52 & 0.50 & 0 & 1 \\
\hline Religious group & 0.07 & 0.25 & 0 & 1 \\
\hline Support group & 0.03 & 0.17 & 0 & 1 \\
\hline Any informal support & 0.80 & 0.40 & 0 & 1 \\
\hline Friend & 0.63 & 0.48 & 0 & 1 \\
\hline Roommate & 0.28 & 0.45 & 0 & 1 \\
\hline Significant other & 0.36 & 0.48 & 0 & 1 \\
\hline Individual-level Controls* & Mean & SD & Min & Max \\
\hline Age & 3.60 & 1.92 & 1 & 10 \\
\hline Mother’s educational attainment & 5.19 & 1.63 & 1 & 8 \\
\hline Father's educational attainment & 5.33 & 1.74 & 1 & 8 \\
\hline Year & 2012 & 1.73 & 2009 & 2015 \\
\hline White & 70.28 & & 0 & 1 \\
\hline Non-white & 29.72 & & 0 & 1 \\
\hline Male & 35.07 & & 0 & 1 \\
\hline Female & 64.93 & & 0 & 1 \\
\hline Heterosexual & .92 & .27 & 0 & 1 \\
\hline Year in School & 2.71 & 1.28 & 1 & 9 \\
\hline Endorsed stigma scale score & 2.64 & 2.59 & 0 & 15 \\
\hline
\end{tabular}

*Note: Restricted to main analysis sample. 
Table 4. Multilevel Logistic Regressions Predicting Mental Health Conditions

\begin{tabular}{|c|c|c|c|c|c|}
\hline & $\begin{array}{c}(1) \\
\text { Depression }\end{array}$ & $\begin{array}{c}(2) \\
\text { Anxiety }\end{array}$ & $\begin{array}{c}(3) \\
\text { Suicidal } \\
\text { Ideation }\end{array}$ & $\begin{array}{c}(4) \\
\text { Self-Injury }\end{array}$ & $\begin{array}{c}(5) \\
\text { Any MH } \\
\text { Condition }\end{array}$ \\
\hline \multicolumn{6}{|l|}{$\underline{\text { School-level variables }}$} \\
\hline Mean endorsed stigma scale & 0.950 & 1.075 & $0.807^{*}$ & $0.861^{*}$ & 0.921 \\
\hline score & $(0.0757)$ & $(0.117)$ & $(0.0765)$ & $(0.0521)$ & $(0.0627)$ \\
\hline Residential campus & $0.808^{* * *}$ & $0.758 * * *$ & 0.912 & $0.907^{*}$ & $0.822 * * *$ \\
\hline (ref: non-residential) & $(0.0424)$ & $(0.0552)$ & $(0.0561)$ & $(0.0364)$ & $(0.0374)$ \\
\hline Highly residential campus & $0.783^{* *}$ & $0.570 * * *$ & 0.934 & 1.010 & $0.789 * *$ \\
\hline (ref: non-residential) & $(0.0672)$ & $(0.0684)$ & $(0.0921)$ & $(0.0630)$ & $(0.0583)$ \\
\hline Public institution & 1.021 & 1.092 & $0.862^{*}$ & $0.903^{*}$ & 0.995 \\
\hline (ref: private) & $(0.0634)$ & $(0.0959)$ & $(0.0600)$ & $(0.0387)$ & $(0.0533)$ \\
\hline Medium size institution) & 1.008 & $0.705^{* *}$ & 0.935 & $0.870+$ & 0.890 \\
\hline (ref: small) & $(0.0966)$ & $(0.0925)$ & $(0.105)$ & $(0.0623)$ & $(0.0730)$ \\
\hline Large size institution & 1.013 & $0.705^{*}$ & 0.905 & 0.889 & 0.900 \\
\hline (ref: small) & $(0.111)$ & $(0.106)$ & $(0.116)$ & $(0.0734)$ & $(0.0841)$ \\
\hline \multicolumn{6}{|l|}{$\underline{\text { Individual-level controls }}$} \\
\hline \multirow[t]{2}{*}{ Endorsed stigma scale score } & $1.073 * * *$ & $1.025 * * *$ & $1.035^{* * *}$ & $1.019 * * *$ & $1.040^{* * *}$ \\
\hline & $(0.00435)$ & $(0.00493)$ & $(0.00602)$ & $(0.00430)$ & $(0.00347)$ \\
\hline \multirow[t]{2}{*}{ Age } & 1.001 & $1.023 * *$ & $0.978^{*}$ & $0.892 * * *$ & $0.970 * * *$ \\
\hline & $(0.00791)$ & $(0.00897)$ & $(0.0112)$ & $(0.00816)$ & $(0.00632)$ \\
\hline \multirow[t]{2}{*}{ White (ref: non-white) } & $0.786 * * *$ & $1.134 * * *$ & $0.883^{* * *}$ & $1.050+$ & $0.920 * * *$ \\
\hline & $(0.0194)$ & $(0.0333)$ & $(0.0306)$ & $(0.0265)$ & $(0.0185)$ \\
\hline \multirow[t]{2}{*}{ Female (ref: Male) } & 1.031 & $1.848 * * *$ & 0.992 & $1.097 * * *$ & $1.158^{* * *}$ \\
\hline & $(0.0238)$ & $(0.0529)$ & $(0.0321)$ & $(0.0255)$ & $(0.0214)$ \\
\hline Mother's educational & $0.963 * * *$ & $0.962 * * *$ & 0.989 & 1.002 & $0.982 * *$ \\
\hline attainment & $(0.00778)$ & $(0.00886)$ & $(0.0113)$ & $(0.00833)$ & $(0.00642)$ \\
\hline Father's educational & 0.992 & 0.993 & 0.997 & 1.009 & 0.996 \\
\hline attainment & $(0.00739)$ & $(0.00839)$ & $(0.0105)$ & $(0.00775)$ & $(0.00601)$ \\
\hline \multirow[t]{2}{*}{ Year } & 1.009 & $1.184 * * *$ & $1.057^{* * *}$ & $1.014+$ & $1.036^{* * *}$ \\
\hline & $(0.00817)$ & $(0.0117)$ & $(0.0112)$ & $(0.00742)$ & $(0.00682)$ \\
\hline \multicolumn{6}{|l|}{$\underline{\text { Random-effects }}$} \\
\hline \multirow[t]{2}{*}{ Intercept variance } & 0.120 & 0.184 & 0.115 & 0.060 & 0.108 \\
\hline & $(0.017)$ & $(0.022)$ & $(0.022)$ & $(0.020)$ & $(0.015)$ \\
\hline $\mathrm{N}$ - individuals & 62710 & 62710 & 62710 & 62710 & 62710 \\
\hline $\mathrm{N}$ - schools & 75 & 75 & 75 & 75 & 75 \\
\hline
\end{tabular}

Note: Regressions also control for school-level academic rank, school-level type (BA, MA, or doctorate granting), individual-level sexual orientation and year in current degree. Odds ratios shown. Standard errors in parenthesis. $+=\mathrm{p}<0.10, *=\mathrm{p}<0.05, * *=\mathrm{p}<0.01, * * *=\mathrm{p}<0.001$ 
Table 5. Multilevel Logistic Regressions Predicting Medication Use

\begin{tabular}{|c|c|c|c|c|c|}
\hline & $\begin{array}{l}\text { (1) } \\
\text { Depression } \\
\text { Medication }\end{array}$ & $\begin{array}{c}(2) \\
\text { Anxiety } \\
\text { Medication }\end{array}$ & $\begin{array}{c}(3) \\
\text { Sleeping } \\
\text { Medication }\end{array}$ & $\begin{array}{l}\text { (4) } \\
\text { Psycho- } \\
\text { stimulants }\end{array}$ & $\begin{array}{c}\text { (5) } \\
\text { Any } \\
\text { Medication }\end{array}$ \\
\hline \multicolumn{6}{|l|}{ School-level variables } \\
\hline $\begin{array}{l}\text { Mean endorsed stigma scale } \\
\text { score }\end{array}$ & $\begin{array}{l}0.695^{* *} \\
(0.0920)\end{array}$ & $\begin{array}{l}0.711 * \\
(0.102)\end{array}$ & $\begin{array}{c}0.797 \\
(0.115)\end{array}$ & $\begin{array}{l}0.700+ \\
(0.139)\end{array}$ & $\begin{array}{l}0.692 * * \\
(0.0846)\end{array}$ \\
\hline $\begin{array}{l}\text { Residential campus } \\
\text { (ref: non-residential) }\end{array}$ & $\begin{array}{c}1.136 \\
(0.100)\end{array}$ & $\begin{array}{l}1.080 \\
(0.100)\end{array}$ & $\begin{array}{c}1.035 \\
(0.0975)\end{array}$ & $\begin{array}{l}1.256+ \\
(0.169)\end{array}$ & $\begin{array}{c}1.149+ \\
(0.0935)\end{array}$ \\
\hline $\begin{array}{l}\text { Highly residential campus } \\
\text { (ref: non-residential) }\end{array}$ & $\begin{array}{c}1.128 \\
(0.160)\end{array}$ & $\begin{array}{c}0.946 \\
(0.143)\end{array}$ & $\begin{array}{c}1.079 \\
(0.160)\end{array}$ & $\begin{array}{c}1.110 \\
(0.238)\end{array}$ & $\begin{array}{l}1.086 \\
(0.143)\end{array}$ \\
\hline $\begin{array}{l}\text { Public institution } \\
\text { (ref: private) }\end{array}$ & $\begin{array}{l}1.034 \\
(0.105)\end{array}$ & $\begin{array}{l}1.108 \\
(0.117)\end{array}$ & $\begin{array}{c}1.012 \\
(0.103)\end{array}$ & $\begin{array}{c}0.985 \\
(0.153)\end{array}$ & $\begin{array}{l}1.047 \\
(0.100)\end{array}$ \\
\hline $\begin{array}{l}\text { Medium size institution) } \\
\text { (ref: small) }\end{array}$ & $\begin{array}{c}1.131 \\
(0.177)\end{array}$ & $\begin{array}{l}1.175 \\
(0.195)\end{array}$ & $\begin{array}{l}1.044 \\
(0.176)\end{array}$ & $\begin{array}{l}1.024 \\
(0.243)\end{array}$ & $\begin{array}{l}1.063 \\
(0.155)\end{array}$ \\
\hline $\begin{array}{l}\text { Large size institution } \\
\quad \text { (ref: small) }\end{array}$ & $\begin{array}{l}1.262 \\
(0.226)\end{array}$ & $\begin{array}{l}1.263 \\
(0.243)\end{array}$ & $\begin{array}{l}1.252 \\
(0.241)\end{array}$ & $\begin{array}{c}1.111 \\
(0.304)\end{array}$ & $\begin{array}{l}1.202 \\
(0.201)\end{array}$ \\
\hline \multicolumn{6}{|l|}{ Individual-level controls } \\
\hline Endorsed stigma scale score & $\begin{array}{l}0.886 * * * \\
(0.00726)\end{array}$ & $\begin{array}{l}0.903 * * * \\
(0.00939)\end{array}$ & $\begin{array}{l}0.970 * * \\
(0.0111)\end{array}$ & $\begin{array}{l}0.931^{* * *} \\
(0.0101)\end{array}$ & $\begin{array}{l}0.901^{* * *} \\
(0.00604)\end{array}$ \\
\hline Age & $\begin{array}{l}1.212^{* * *} \\
(0.0165)\end{array}$ & $\begin{array}{l}1.206^{* * *} \\
(0.0194)\end{array}$ & $\begin{array}{l}1.216^{* * *} \\
(0.0224)\end{array}$ & $\begin{array}{l}1.084^{* * *} \\
(0.0220)\end{array}$ & $\begin{array}{l}1.205^{* * *} \\
(0.0147)\end{array}$ \\
\hline White (ref: non-white) & $\begin{array}{c}2.072^{* * *} \\
(0.103)\end{array}$ & $\begin{array}{c}1.882^{* * *} \\
(0.118)\end{array}$ & $\begin{array}{l}1.395^{* * *} \\
(0.0984)\end{array}$ & $\begin{array}{c}1.635^{* * *} \\
(0.113)\end{array}$ & $\begin{array}{l}1.928 * * * \\
(0.0788)\end{array}$ \\
\hline Female (ref: Male) & $\begin{array}{l}1.791^{* * *} \\
(0.0803)\end{array}$ & $\begin{array}{l}1.574 * * * \\
(0.0893)\end{array}$ & $\begin{array}{l}1.349 * * * \\
(0.0894)\end{array}$ & $\begin{array}{l}0.714^{* * *} \\
(0.0399)\end{array}$ & $\begin{array}{l}1.288 * * * \\
(0.0469)\end{array}$ \\
\hline $\begin{array}{l}\text { Mother's educational } \\
\text { attainment }\end{array}$ & $\begin{array}{l}1.063^{* * *} \\
(0.0156)\end{array}$ & $\begin{array}{l}1.063^{* * *} \\
(0.0196)\end{array}$ & $\begin{array}{c}1.032 \\
(0.0227)\end{array}$ & $\begin{array}{l}1.107 * * * \\
(0.0233)\end{array}$ & $\begin{array}{l}1.093^{* * *} \\
(0.0138)\end{array}$ \\
\hline $\begin{array}{l}\text { Father's educational } \\
\text { attainment }\end{array}$ & $\begin{array}{l}1.045^{* *} \\
(0.0141)\end{array}$ & $\begin{array}{c}0.981 \\
(0.0164)\end{array}$ & $\begin{array}{c}1.014 \\
(0.0204)\end{array}$ & $\begin{array}{l}1.070^{* * *} \\
(0.0207)\end{array}$ & $\begin{array}{c}1.021+ \\
(0.0117)\end{array}$ \\
\hline Year & $\begin{array}{c}1.004 \\
(0.0139)\end{array}$ & $\begin{array}{c}1.001 \\
(0.0166)\end{array}$ & $\begin{array}{l}0.883^{* * *} \\
(0.0165)\end{array}$ & $\begin{array}{c}1.019 \\
(0.0201)\end{array}$ & $\begin{array}{c}1.005 \\
(0.0123)\end{array}$ \\
\hline$\underline{\text { Random-effects }}$ & & & & & \\
\hline Intercept variance & $\begin{array}{c}0.190 \\
(0.029)\end{array}$ & $\begin{array}{c}0.164 \\
(0.038)\end{array}$ & $\begin{array}{c}0.091 \\
(0.067)\end{array}$ & $\begin{array}{c}0.297 \\
(0.043)\end{array}$ & $\begin{array}{c}0.187 \\
(0.026)\end{array}$ \\
\hline $\mathrm{N}$ - individuals & 21107 & 21107 & 21107 & 21107 & 21107 \\
\hline $\mathrm{N}$ - schools & 75 & 75 & 75 & 75 & 75 \\
\hline
\end{tabular}

Note: Regressions also control for all individual-level controls shown in Table 3 as well as school-level academic rank and school-level type (BA, MA, or doctorate granting). Odds ratios shown. Standard errors in parenthesis. $+=\mathrm{p}<0.10, *=\mathrm{p}<0.05, * *=\mathrm{p}<0.01, * * *=\mathrm{p}<0.001$ 
Table 6. Multilevel Logistic Regressions Predicting Seeking Counseling and Therapy

\begin{tabular}{|c|c|c|c|c|}
\hline & $\begin{array}{c}\text { (1) } \\
\text { Institution's } \\
\text { Student } \\
\text { Services }\end{array}$ & $\begin{array}{c}(2) \\
\text { Local Provider }\end{array}$ & $\begin{array}{l}\text { (3) } \\
\text { Hometown } \\
\text { Provider }\end{array}$ & $\begin{array}{c}\text { (4) } \\
\text { Any } \\
\text { Counseling or } \\
\text { Therapy }\end{array}$ \\
\hline \multicolumn{5}{|l|}{$\underline{\text { School-level variables }}$} \\
\hline \multirow[t]{2}{*}{ Mean endorsed stigma scale score } & $0.472 * *$ & 0.832 & $0.707 * *$ & $0.684^{* * *}$ \\
\hline & $(0.109)$ & $(0.169)$ & $(0.0864)$ & -0.0683 \\
\hline \multirow[t]{2}{*}{ Residential campus (ref: non-residential) } & 0.998 & 0.912 & $1.309 * *$ & $1.140^{*}$ \\
\hline & $(0.159)$ & $(0.124)$ & $(0.116)$ & -0.0756 \\
\hline \multirow[t]{2}{*}{ Highly residential campus (ref: non-residential) } & $2.853 * * *$ & 0.858 & $1.613^{* * *}$ & $1.399 * *$ \\
\hline & $(0.752)$ & $(0.185)$ & $(0.203)$ & -0.146 \\
\hline \multirow[t]{2}{*}{ Public institution (ref: private) } & $0.636^{*}$ & $1.321+$ & 1.112 & 1.085 \\
\hline & $(0.128)$ & $(0.204)$ & $(0.0919)$ & -0.08 \\
\hline \multirow[t]{2}{*}{ Medium size institution (ref: small) } & 1.575 & 1.230 & 1.197 & 1.113 \\
\hline & $(0.459)$ & $(0.299)$ & $(0.168)$ & -0.13 \\
\hline \multirow[t]{2}{*}{ Large size institution (ref: small) } & $1.993 *$ & 1.544 & 1.182 & 1.13 \\
\hline & $(0.670)$ & $(0.431)$ & $(0.191)$ & -0.152 \\
\hline \multicolumn{5}{|l|}{$\underline{\text { Individual-level controls }^{\#}}$} \\
\hline \multirow[t]{2}{*}{ Endorsed stigma scale score } & $0.906^{* * *}$ & $0.859 * * *$ & $0.876^{* * *}$ & $0.881^{* * *}$ \\
\hline & $(0.00730)$ & $(0.0111)$ & $(0.00925)$ & -0.00566 \\
\hline \multicolumn{5}{|l|}{$\underline{\text { Random-effects }}$} \\
\hline \multirow[t]{2}{*}{ Intercept variance } & 0.432 & 0.294 & 0.083 & 0.126 \\
\hline & $(0.050)$ & $(0.047)$ & $(0.064)$ & $(0.024)$ \\
\hline $\mathrm{N}$ - individuals & 21093 & 21093 & 21093 & 21093 \\
\hline $\mathrm{N}$ - schools & 75 & 75 & 75 & 75 \\
\hline
\end{tabular}

Note: Regressions also control for school-level academic rank and school-level type (BA, MA, or doctorate granting). Odds ratios shown. Standard errors in parenthesis. \# Individual level controls include age, race, sex, parent's educational attainment, sexual orientation, and year in current degree.

$+=\mathrm{p}<0.10, *=\mathrm{p}<0.05, * *=\mathrm{p}<0.01, * * *=\mathrm{p}<0.001$ 
Table 7. Multilevel Logistic Regressions Predicting Seeking Informal Support

\begin{tabular}{|c|c|c|c|c|c|c|c|}
\hline & $\begin{array}{c}(1) \\
\text { Family } \\
\text { Member }\end{array}$ & $\begin{array}{c}(2) \\
\text { Religious } \\
\text { Group }\end{array}$ & $\begin{array}{c}\text { (3) } \\
\text { Support Group }\end{array}$ & $\begin{array}{l}\text { (4) } \\
\text { Friend }\end{array}$ & $\begin{array}{c}\text { (5) } \\
\text { Roommate }\end{array}$ & $\begin{array}{c}(6) \\
\text { Significant } \\
\text { Other }\end{array}$ & $\begin{array}{c}(7) \\
\text { Any Informal } \\
\text { Support }\end{array}$ \\
\hline \multicolumn{8}{|l|}{ School-level variables } \\
\hline \multirow[t]{2}{*}{ Mean endorsed stigma scale score } & $0.789 * *$ & $1.537+$ & 0.778 & $0.828^{*}$ & 0.957 & $0.751^{* * *}$ & $0.794 *$ \\
\hline & $(0.0695)$ & $(0.373)$ & $(0.200)$ & $(0.0623)$ & $(0.169)$ & $(0.0558)$ & $(0.0862)$ \\
\hline \multirow[t]{2}{*}{ Residential campus (ref: non-residential) } & 1.011 & $1.389 *$ & 0.951 & 0.958 & $1.783^{* * *}$ & 0.971 & 0.993 \\
\hline & $(0.0543)$ & $(0.222)$ & $(0.151)$ & $(0.0438)$ & $(0.207)$ & $(0.0443)$ & $(0.0645)$ \\
\hline \multirow[t]{2}{*}{ Highly residential campus (ref: non-residential) } & 0.986 & 1.324 & 1.074 & 1.079 & $1.888^{* * *}$ & 1.027 & 1.031 \\
\hline & $(0.0866)$ & $(0.347)$ & $(0.278)$ & $(0.0802)$ & $(0.359)$ & $(0.0747)$ & $(0.114)$ \\
\hline \multirow[t]{2}{*}{ Public institution (ref: private) } & 0.954 & 1.091 & 1.139 & $1.177^{* *}$ & 0.974 & $0.868^{* *}$ & $1.176^{*}$ \\
\hline & $(0.0587)$ & $(0.207)$ & $(0.211)$ & $(0.0599)$ & $(0.137)$ & $(0.0435)$ & $(0.0913)$ \\
\hline \multirow[t]{2}{*}{ Medium size institution (ref: small) } & 0.935 & 0.623 & 0.839 & 1.020 & 0.783 & 0.938 & 1.064 \\
\hline & $(0.0975)$ & $(0.186)$ & $(0.267)$ & $(0.0927)$ & $(0.170)$ & $(0.0836)$ & $(0.139)$ \\
\hline \multirow[t]{2}{*}{ Large size institution (ref: small) } & 1.024 & $0.429 *$ & 0.910 & 1.175 & 0.773 & 0.968 & 1.117 \\
\hline & $(0.125)$ & $(0.146)$ & $(0.328)$ & $(0.125)$ & $(0.193)$ & $(0.101)$ & $(0.172)$ \\
\hline \multicolumn{8}{|l|}{$\underline{\text { Individual-level controls }^{\#}}$} \\
\hline \multirow[t]{2}{*}{ Endorsed stigma scale score } & $0.926 * * *$ & $0.955^{* * *}$ & $0.893^{* * *}$ & $0.905^{* * *}$ & $0.949 * * *$ & $0.927 * * *$ & $0.896^{* * *}$ \\
\hline & $(0.00518)$ & $(0.0106)$ & $(0.0170)$ & $(0.00514)$ & $(0.00617)$ & $(0.00552)$ & $(0.00584)$ \\
\hline \multicolumn{8}{|l|}{$\underline{\text { Random-effects }}$} \\
\hline \multirow[t]{2}{*}{ Intercept variance } & 0.081 & 0.374 & 0.258 & 0.00003 & 0.289 & 0.0000086 & 0.095 \\
\hline & $(0.025)$ & $(0.048)$ & $(0.070)$ & $(0.039)$ & $(0.034)$ & $(0.036)$ & $(0.032)$ \\
\hline $\mathrm{N}$ - individuals & 19384 & 19384 & 19384 & 19384 & 19384 & 19384 & 19384 \\
\hline $\mathrm{N}-$ schools & 68 & 68 & 68 & 68 & 68 & 68 & 68 \\
\hline
\end{tabular}

Note: Regressions also control for school-level academic rank and school-level type (BA, MA, or doctorate granting). Odds ratios shown. Standard errors in parenthesis. \# Individual level controls include age, race, sex, parent's educational attainment, sexual orientation, and year in current degree.

$+=\mathrm{p}<0.10, *=\mathrm{p}<0.05, * *=\mathrm{p}<0.01, * * *=\mathrm{p}<0.001$ 
Figure 1. Distribution of School-Level Prevalence of Four “Any” Outcomes

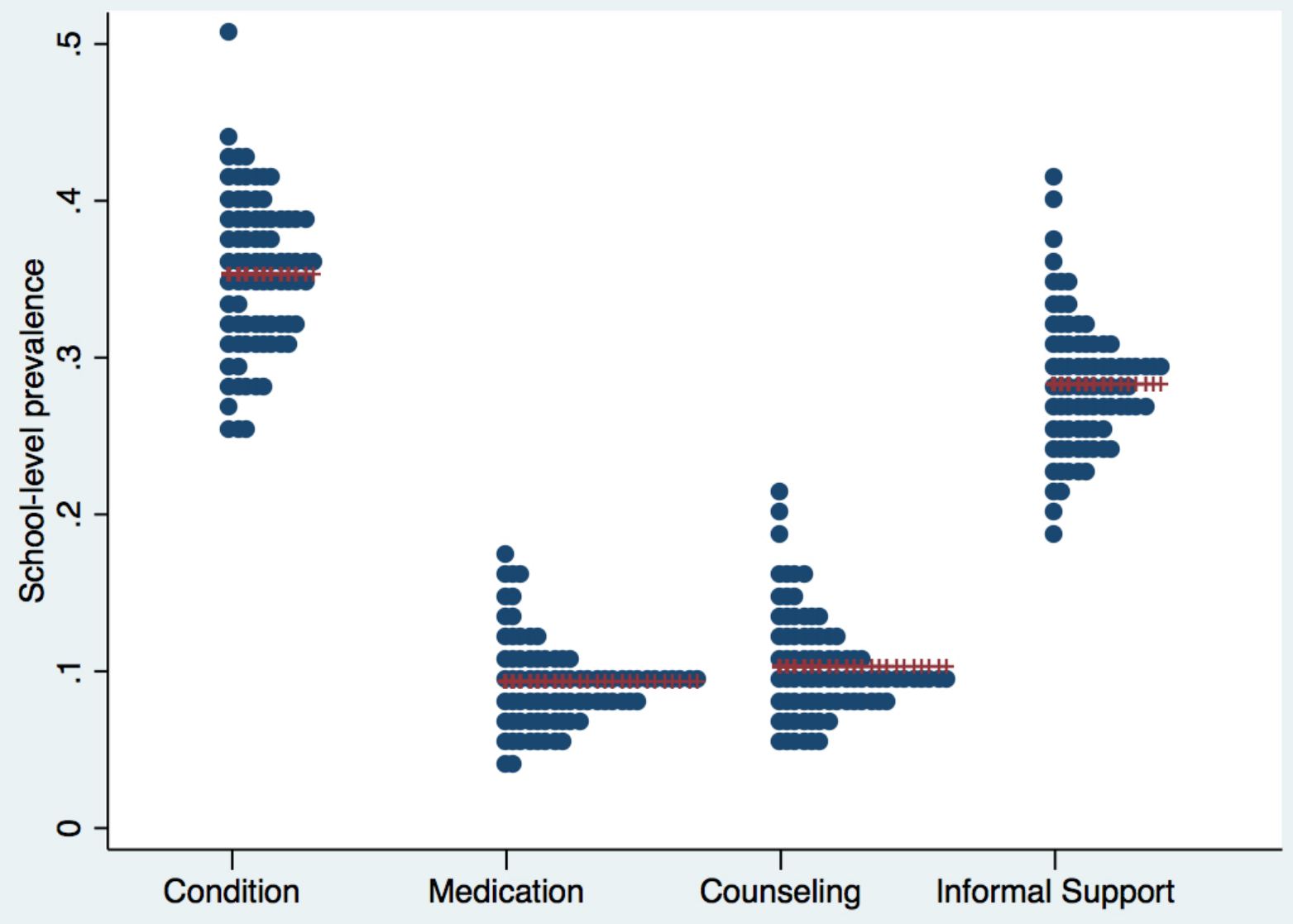

Note: Each dot represents one school. 
Figure 2. School-Level Prevalence of Four “Any” Outcomes by School-Level Stigma

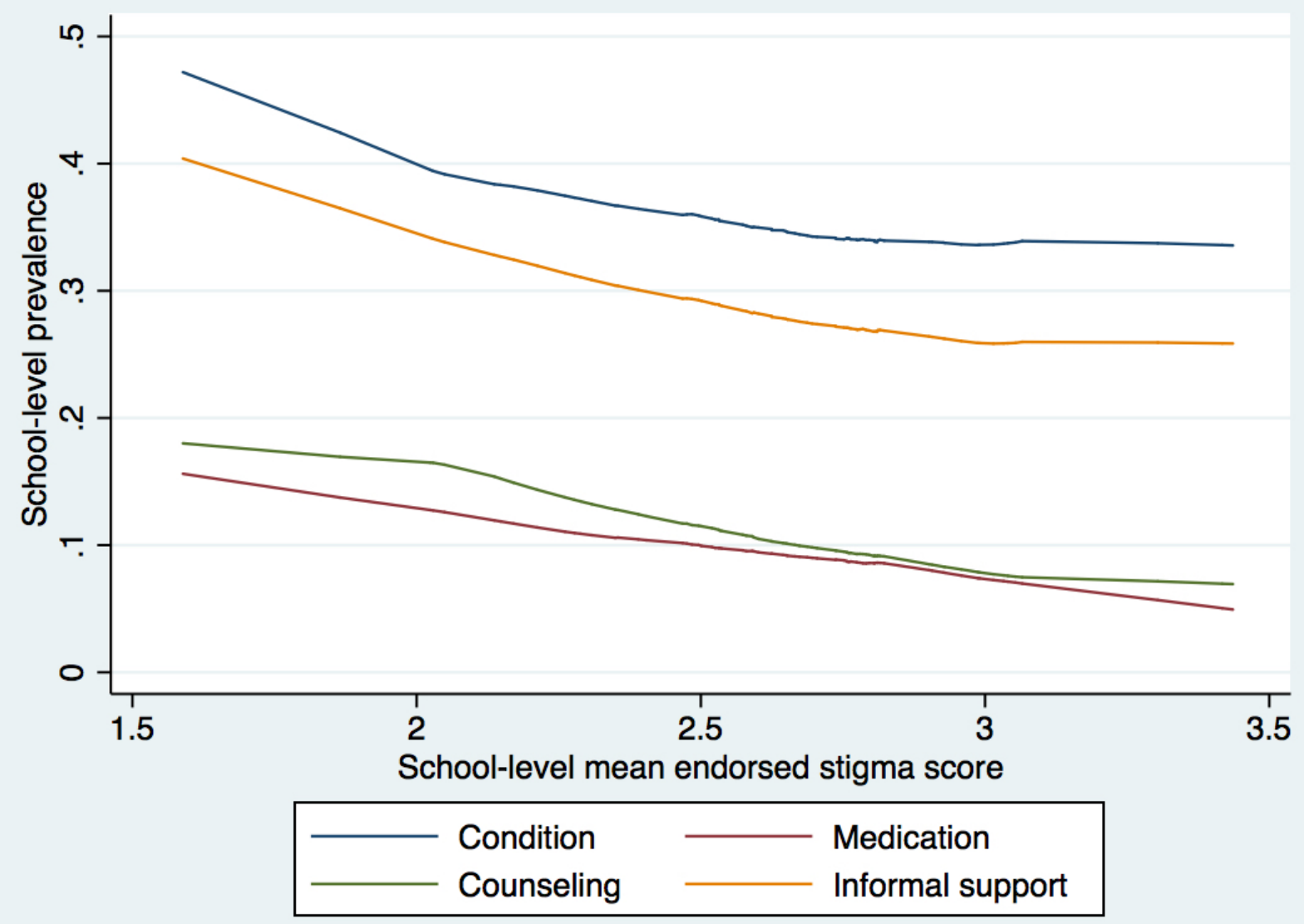

Note: Lowess curve estimates shown. 